usually obvious which species are rare and in need of conservation. The habitat requirements of such species are mostly known and several chapters deal with how sufficient autecological information has been obtained to devise successful conservation programmes.

The conservation problems of northwest Europe pale into insignificance in comparison with those of such species-rich areas as the Cape of Good Hope with 1,244 threatened plant species. Very few of these have been studied in any detail and the two species discussed exemplify the difficulties. Field work undertaken to promote their conservation has demonstrated the importance of fire in stimulating germination, but, at least in the case of Staavia dodii, all attempts to germinate seed outside the natural field environment - including artificial fire - have failed, making garden cultivation impractical as a conservation measure. The concentration of the few remaining populations of so many species in a small area poses serious management problems when so little is known of their autecology.

However, by far the most critical situation exists in the tropical rain forests where a fair proportion of the species are still undescribed. It can be reliably stated that if the present rate of destruction continues, and it is likely to, many species will become extinct before they can be described. There is no doubt that this is the vegetation type in which most extinctions are taking place and that this is a loss not just to biological diversity but to the resources of the world of value to mankind. The four chapters in Section 2 of the book, "Tropical Forests - The Conservation Priority", are an excellent statement of the problem and how it should be tackled. The only sensible approach is to try to conserve areas of great species diversity and hope thereby to protect the maximum number of species. Quite large areas may be required, as a typical tree species may have an average density of 1 per 5 hectares and be dioecious - though sometimes facultatively apomictic. Dransfield's paper describes how controlled cropping can be compatible with conservation.

One chapter, discussing the conservation of lower plants, points to the similarities with the situation in tropical rain forests - a lack of floras and lack of knowledge of species distributions, most species not being amenable to cultivation, meaning that conservation in their native habitats is the only hope for their survival.

The varied topics covered make this work an excellent and much-needed world picture of the present state of plant conservation, although the quality of the individual contributions is very variable. Unfortunately the book promises a bleak future, both environmentally and economically, if there is no improvement.

H. McAllister is the Assistant Director of the Botanic Gardens, University of Liverpool.

\title{
Slimmer tracts for gut physiologists
}

\section{G.J. Dockray}

Physiology of the Gastrointestinal Tract, Vols 1 and 2. Edited by Leonard R. Johnson. Pp.1,492. ISBN 0-89004-440-6. (Raven: 1981.) Two-volume set \$165.

WHEN the American Physiological Society devoted a section of their Handbook of Physiology to the gut in the late 1960s, it needed five volumes containing well over 100 chapters to produce a comprehensive account of the subject. After a period of unprecedented expansion in our knowledge of gut function it comes as a pleasant surprise to find that the present work consists of two volumes and less than half the number of chapters needed over a decade ago. Unfortunately, the feeling of relief is tempered by the fact that this brevity has been partly achieved by a selective approach. There is, for instance, relatively little attention given to the liver, salivary glands, comparative and evolutionary aspects, and control of nutrient intake. The omissions are regrettable, not least because they are inimical to the editors' objective of producing a definitive treatise.

This is not to say, however, that there are not good reasons to justify a relatively economical approach in reviewing the present state of gastrointestinal physiology. Recent advances in this field have dealt very largely with the elucidation of events at the cellular and sub-cellular levels. The present volumes both reflect the recent areas of progress and illustrate how it is possible to explain fundamental aspects of organization in a way that readily reconciles fragmentary and even contradictory work from the past.

A series of chapters at the start of the first volume, and at the end of the second, deals with general aspects of digestive physiology and related topics. The major gut functions - secretion, motility and absorption - are covered in separate sections. In each case there are contributions dealing with functional morphology and molecular mechanisms, and these serve to provide a context for chapters dealing with the integrative aspects of each system. The treatment works well, and in particular makes it easy to see how physiological mechanisms of the gut can be related to the functions of other organ systems. Indeed, it is worth noting that a significant part of our understanding of such basic cellular mechanisms as membrane transport and secretion have been derived from studies on the alimentary tract and associated organs. For this reason these two volumes will be of interest and value to many whose main concerns lie outside the gut, but who nevertheless wish to understand recent developments in gut physiology. The gut chauvinist should not, however, feel neglected since there are, for example, chapters dealing with such singularly digestive subjects as dietary fibre and gut gas.

The contributors are nearly all wellrecognized authorities in their fields and most have taken the opportunity to produce a comprehensive assessment of the present state of their subject. This, as much as anything, should serve to ensure the success and value of the work as a whole, since it is likely to be some time before such a strong team will again feel tempted to review their topics at length and in unison. In the present climate of recession and austerity it would be surprising if there were many who felt inclined to buy this work for themselves; they need feel no guilt, however, about persuading their librarians to make the investment.

G.J. Dockray is Reader in Physiology at the University of Liverpool.

\section{Cladistics clarified}

\section{Alan J. Charig}

Phylogenetics: The Theory and Practice of Phylogenetic Systematics. By E.O. Wiley. Pp.439. ISBN 0-471-05975-7. (Wiley: 1981.) £27.75, $\$ 49.90$.

WILLI Hennig is rightly regarded as the father of phylogenetic systematics; his book, Phylogenetic Systematics (University of Illinois Press, 1966) is the fundamental source of this important approach towards the reconstruction of evolutionary history and the classification of living organisms. It is therefore appropriate that Wiley's new book on this subject should use a photograph of Hennig as its frontispiece. During the last decade of Hennig's life (he died in 1976) the school of thought which he had founded - now loosely referred to as "cladistics" attracted an ever-increasing volume of attention and comment.

Within the last couple of years, however, the Hennigian school has sprouted the new, very different and even more controversial offshoot, "transformed cladistics" ("natural order systematics" in my terminology). The works of Popper on the philosophy of science undoubtedly exerted a major influence upon this schismatic development during its prolonged gestation, but Popper himself seems to have rejected it subsequently. Indeed, were Father Hennig still alive today he too would have rejected it wholeheartedly; his arch-opponents would have been, not Mayr and Simpson, but leading transformed cladists like Nelson and Patterson.

The approach of the transformed cladists is essentially typological; they 